\title{
Temporomandibular joint disk adhesion: evidence from magnetic resonance images
}

\author{
Adesão do disco da articulação temporomandibular: evidências em ressonância magnética
}

\author{
Daniela Pita de MELO' \\ Luciana Soares de Andrade Freitas OLIVEIRA ${ }^{2}$ \\ Ana Clara Alves de CARVALHO² \\ Anne Caroline Costa OENNING ${ }^{3}$ \\ Amanda Katarinny Goes GONZAGA' \\ Paulo Sérgio Flores CAMPOS²
}

\begin{abstract}
This case report has the aim to present an adhesion of the temporomadibular disc to the articular eminence, diagnosed on magnetic resonance imaging images. A 37-year-old female patient with TMJ (temporomandibular joint) disk adhesion on the left side and complaining of bilateral otalgia over the last 2 years is reported in the present article. The patient did not complain of articular pain or clicking, or any other noises of any nature. Clinical observation showed that the patient had restricted jaw opening, with mandibular deviation the left side without correction during mandibular movement. Our diagnostic impression was of partial anterior disk displacement with reduction of the right side disc; and partial anterior disk displacement with reduction and disc disk adhesion with hypo-mobility of the condyle, on the left temporomandibular joint. The peculiarity of this reported case is the fact that besides the bilateral partial anterior disc displacement, there was also found an adhesion of the disc on the left side. In conclusion, the magnetic resonance imaging exam of the temporomandibular joint can be considered an exam of choice for the evaluation of disc positioning and its morphological alterations.
\end{abstract}

Indexing terms: Magnetic resonance spectroscopy. Temporomandibular joint. Temporomandibular joint disc.

\section{RESUMO}

Este trabalho tem como objetivo apresentar um caso clínico de adesão do disco da articulação temporomandibular à eminência articular, diagnosticada através da ressonância magnética. Paciente de 37 anos de idade, sexo feminino, com queixa de crises ocasionais de otalgia bilateral, ao longo dos últimos 2 anos. A paciente não referia dor ou ruídos articulares de qualquer natureza. Clinicamente, apresentava limitação de abertura de boca, com desvio à esquerda sem correção da trajetória ao final do movimento mandibular. A impressão diagnóstica foi de deslocamento anterior parcial, com redução, do disco articular direito; e, para o lado esquerdo, deslocamento anterior parcial, com redução, e adesão do disco articular ao componente temporal, com hipomobilidade do côndilo. A particularidade do caso descrito está justamente no fato de que além do deslocamento parcial anterior, bilateral, existia, também, uma adesão do disco no lado esquerdo. Concluise que o exame de ressonância magnética da articulação temporomandibular pode ser considerado o método de escolha para avaliação do posicionamento do disco articular e suas alterações morfológicas.

Termos de indexação: Espectroscopia de ressonância magnética. Articulação temporomandibular. Disco da articulação temporomandibular.

\section{INTRODUCTION}

The regular movements of the temporomandibular joint (TMJ) primarily depend on the smooth movement of the disk in the joint space, along the fossa and the articular eminence. The condyle must be allowed to rotate, moving along the inferior aspect of the TMJ disk, and the mandibular condyle/disk set must be allowed to glide along the posterior aspect, vertex and lower aspect of the articular eminence, thus providing wide mouth opening movement, in addition to lateral excursion, protrusion and retrusion. Intra-articular alterations may interfere with temporomandibular joint movements and cause mouthopening limitation?

Over the last decades, major advances in imaging diagnosis have contributed to an improved understanding of temporomandibular disorders. The advances in magnetic resonance (MR) of TMJ allowed better visualization of intra-articular structures, especially the TMJ disk, and made it the currently preferred imaging method for the evaluation of disk position and morphological alterations².

\footnotetext{
${ }^{1}$ Universidade Estadual da Paraíba, Centro de Ciências Biológicas e da Saúde, Curso de Odontologia. Rua Baraúnas, 351, Bairro Universitário, 58429500, Campina Grande, PB, Brasil. Correspondência para / Correspondence to: AKG GONZAGA. E-mail: <amandaggonzaga@gmail.com>

${ }^{2}$ Universidade Federal da Bahia, Instituto de Ciências da Saúde, Faculdade de Odontologia, Departamento de Radiologia. Salvador, BA, Brasil

${ }^{3}$ Universidade Estadual de Campinas, Faculdade de Odontologia, Departamento de Diagnóstico Oral. Piracicaba, SP, Brasil.
} 
The evolution of this imaging method has also allowed a more precise diagnosis of cases of TMJ disk adhesion, facilitating its correct manegement ${ }^{2}$.

Disk adhesions are more common along the temporal component, with or without disk displacement. Condyle adhesions are rare and unexpected because this component is movable ${ }^{1}$.

The anchored disk phenomenon (disk adhesion to the articular fossa) eventually prevents the disk from gliding, leading to severe mouth-opening limitation ${ }^{3-5}$. This anchoring may represent the first stage of a process that may evolve to anterior displacement with adhesion, or to osteoarthrosis ${ }^{4-5}$.

More often the disk, once anteriorly displaced, adheres to the articular eminence and becomes an obstacle to the regular movement of the condyle, which is characterized in the following case.

\section{CASE REPORT}

A 37-year-old female patient was referred to a private clinic in order to undergo magnetic resonance imaging (MRI) of the TMJs. The patient complained of occasional episodes of bilateral otalgia over the last 2 years. History of relevant diseases, local trauma, TMJ surgery or usage of continuous medication was not reported. The patient did not refer articular pain, locking, clicking, noise of any kind, bruxism, tightening of teeth, or usage of orthodontic appliance. Clinical examination revealed partially edentulous maxillary and mandibular arches and mouth opening limitation, with deflection of the mandible to the left side without correction of the trajectory at the end of the jaw opening movement.

The MR scans were made in a Signa Horizon system, at magnetic field magnitude of $1.5 \mathrm{~T}$, manufactured by General Electric (Milwaukee, WI, USA), using a bilateral radiofrequency surface coil of $6.5 \times 6.5 \mathrm{~cm}$ in size.

The image sequence of the right (Figure 1) and left (Figure 2) sides in closed-mouth position showed retroposition of the condyle and partial anterior displacement of the lateral segment of the TMJ disk, which gradually returns to its normal position in relation to the articular bone components

In the open-mouth position it was observed asymmetric excursion of the mandibular condyles with hypomobility to the left side. Reduction of the displaced disk was observed in the right side (Figure 3), as well as in the left side (Figure 4). The left articular disk, however, showed little movement in relation to the temporal component and determined the limitation of the condylar translation. The apparent fibrous tissue, viewed as a hyposignal extending from the posterior band of the disk to the articular fossa, may actually be a fibrous band adhesion (Figure 4).

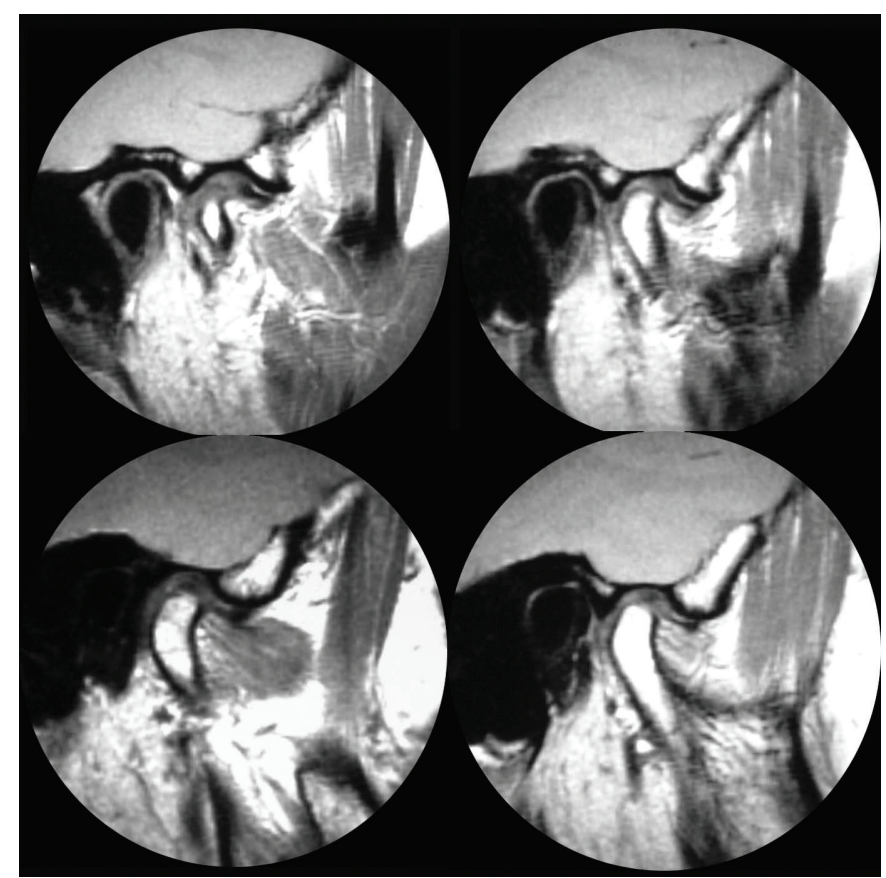

Figure 1. Parasagittal images, closed-mouth, right side. One can observe anterior displacement of the lateral segment of the disk (arrows), which gradually returns to the normal position between the condyle and the articular fossa.

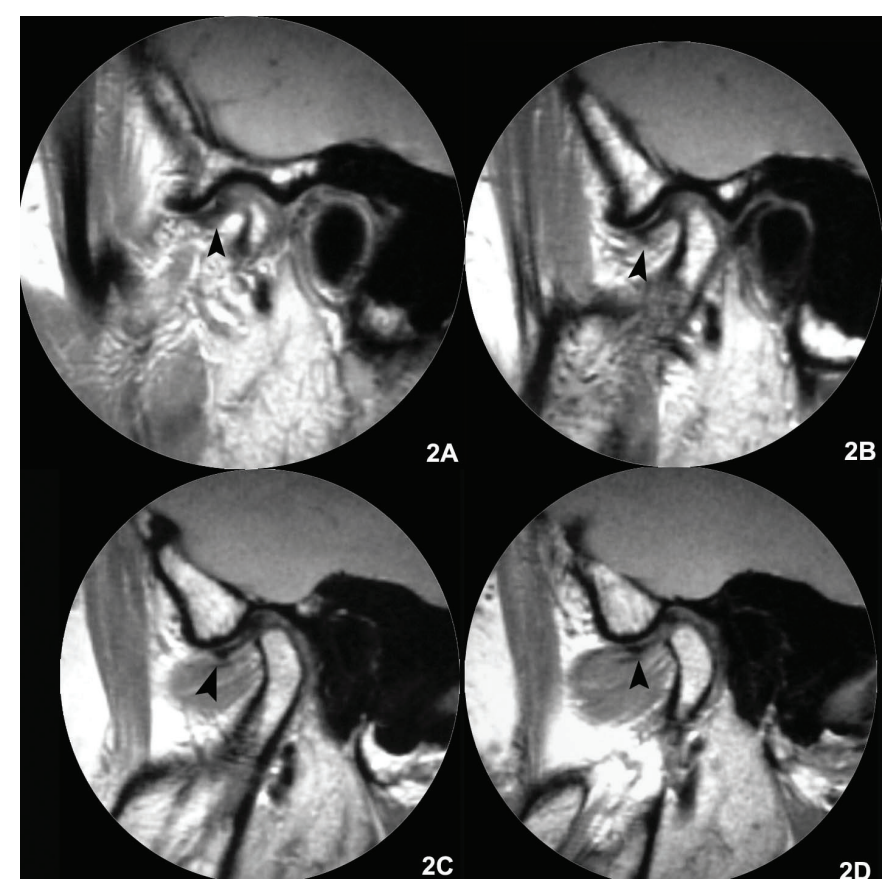

Figure 2. Parasagittal images, closed-mouth, left side. The same situation described for the right side is found here (arrows). 


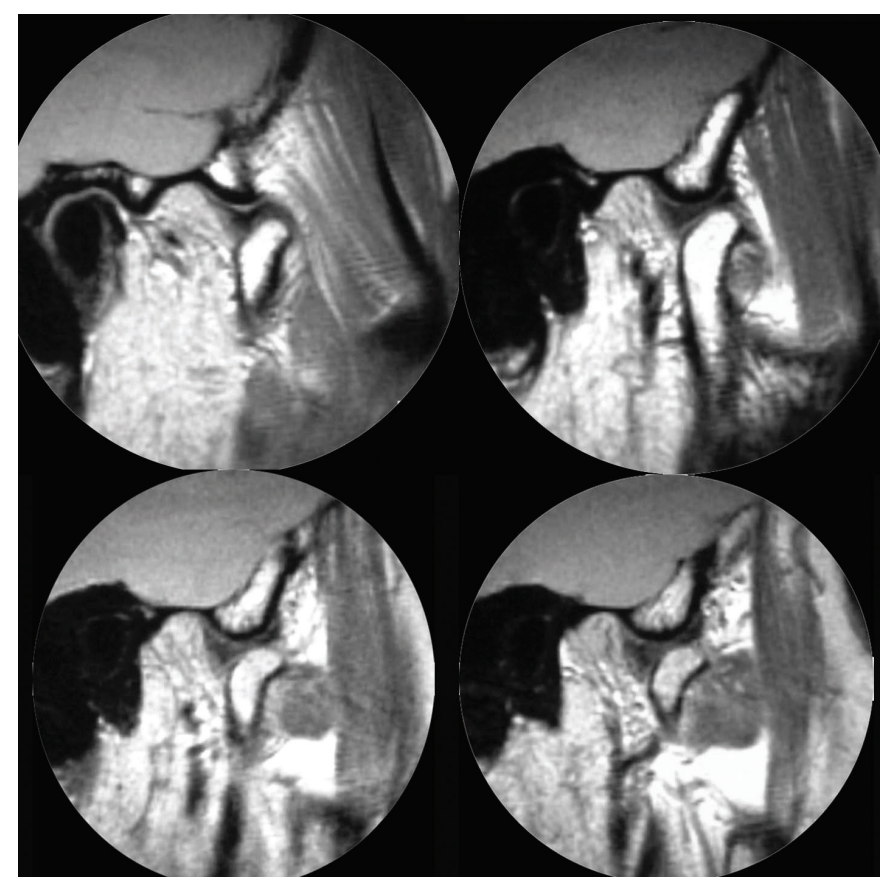

Figure 3. Open-mouth images, right side, showing normal relationship between the disk and the bony components and normal condylar excursion.

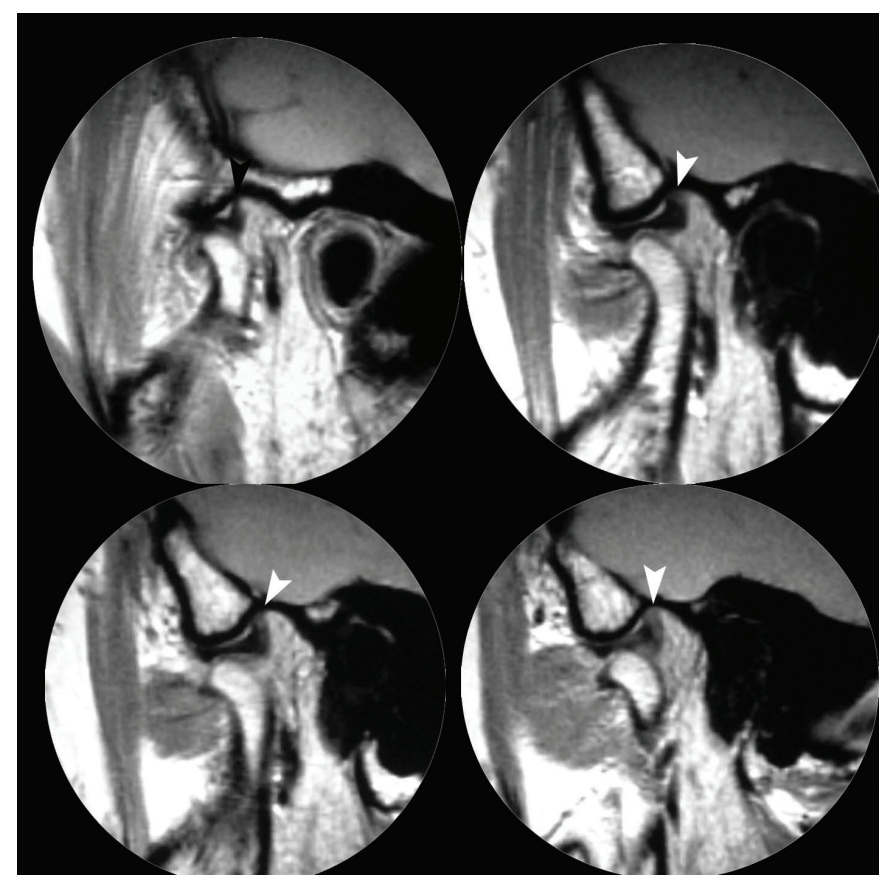

Figure 4. Open-mouth images, showing condylar hypomobility, although the disk is correctly interposed to the articular bony components. The limited motion of the disk is well characterized and the apparent adhesion fibrous band (from the posterior band of the disk to the articular fossa) is very pronounced (arrows).

The diagnostic impression was as follows: a) retropositioning of the right condyle; b) partial anterior displacement, with reduction, of right articular disk; c) retropositioning of the left condyle; d) partial anterior displacement, with reduction, of left articular disk; e) apparent adhesion of left articular disk; f) hypomobility of the left condyle.

Written informed consent was obtained from the patient for publication of this case report.

\section{DISCUSSION}

Mandibular movement requires coordination between condyle, articular disk and masticatory muscles. Whenever a mechanical failure interferes with the normal joint movement, an internal derangement of the TMJS occurs. One of the main causes of internal derangement of the TMJs is the disk displacement ${ }^{4}$.

The posterior ligament of the disk is responsible for maintaining the disk more elevated than the condyle. When partial or total displacement of the disk occurs, this ligament shall also cause reduction of the disk ${ }^{5-7}$. In time, the stretching of the elastic fibers of the upper bundle of the ligament causes weakening of these fibers and make it incapable of replacing the disk in its position when the condyle makes a translation movement ${ }^{2}$.

According to Kaminishi and Davis ${ }^{7}$, disk adhesion may follow synovitis or a hematoma resolution process, and it is more common in the superior articular space. At least eight types of adhesion, mainly fibrous, have been identified in arthroscopies of anteriorly displaced disks.

In addition, the TMJ lubrication system must operate efficiently to ensure that the disk slides properly on the articular surfaces. If this system fails, or when the lubricant fluid is too thin, adhesive forces may act, which shall cause disk adhesion to the articular fossa ${ }^{8}$. It is believed that disk adhesion may be associated with the application of excessive load to the joint ${ }^{8}$ and that this phenomenon is only the first stage of a process that may lead to anterior displacement of the TMJ disk with adhesion ${ }^{5-7}$.

In the present case, the left articular disk was partially displaced and apparently adhered to the posterior segment of the eminence and anterior segment of the articular fossa. The image revealed a tissue in hyposignal extending from the posterior band of the disk to the articular fossa, which may well be a fibrous tissue adhesion.

The reported association between the anterior displacement of the disk and fibrous adhesion is consistent with Sanróman's ${ }^{8}$ findings. The MRI scans and arthroscopy performed by this author confirmed that the most common form of adhesion of anteriorly displaced disks is fibrous adhesion ${ }^{8}$. 
Disk adhesion is normally related to limited condylar translation movement ${ }^{8-10}$, with deviation of the jaw to the affected side during mouth opening ${ }^{8}$. However, there are cases where disk adhesion does not affect the mouth opening movement ${ }^{1}$. In the present case, asymmetric excursion of the condyles with hypomobility of the left side determines mouth opening limitation with deflection of the mandible to the left side, without correction of the trajectory at the end of the jaw opening movement.

It is important to stress that, despite the recapture of the displaced disk, which usually leads to normal condylar excursion, the lack of disk movement may determine condylar hypomobility.

Zhang et al. ${ }^{11}$ evaluated the effect of arthroscopic surgeryforintra-articularadhesions of thetemporomandibular joint. One hundred forty-two patients (159 joints) with intraarticular adhesions, confirmed by arthroscopy, were treated with lysis of the adhesions, intra-articular cleanup surgery, or capsule radiofrequency catheter ablation. One hundred ten patients (123 joints) with disc displacement were treated with the disc repositioning and suturing technique. The total effectiveness rate was $90.14 \%$ (128/142). The effect of arthroscopic surgery on temporomandibular joint intraarticular adhesion was positive. It can increase the mouth's range of motion, improve jaw function, and reduce pain

\section{REFERENCES}

1. Campos PS, Macedo Sobrinho JB, Crusoé-Rebello IM, Pena N, Dantas JA, Mariz AC, et al. Temporomandibular joint disk adhesion without mouth-opening limitation. J Oral Maxillofac Surg. 2008;66(3):551-4. doi:10.1016/j.joms.2006.11.006.

2. Eberhard D, Bantleon HP, Steger W. Functional magnetic resonance imaging of temporomandibular joint disorders. Eur J Orthod. 2000;22(5):489-97. doi: 10.1093/ejo/22.5.489.

3. Nitzan DW, Goldfarb MD, Gati I, Kohen R. Changes in the reducing power of synovial fluid from temporomandibular joints with anchored disk phenomenon. J Oral Maxillofac Surg. 2002;60(7):735-49. doi:10.1053/joms.2002.33238.

4. Nitzan DW, Etsion I. Adhesive force: the underlying cause of the disk anchorage to the fossa and/or eminence in the tempomandibular joint- a new concept. Int J Maxillofac Surg. 2002;31(1):94-9. doi:10.1054/ijom.2001.0153.

5. Kaneyama K, Segami N, Shin-Ichi T, Fujimura K, Sato J, Nagao T. Anchored disk phenomenon with a normally positioned disk in the temporomandibular joint: characteristics and behaviour. Br J Oral Maxillofac Surg. 2007;45(4):279-83. doi:10.1016/j. bjoms.2006.08.021.

6. Nitzan DW, Maramary Y. The anchored disk phenomenon: a proposed etiology for sudden-onset, severe, and persistent closed during jaw movement. Mosby ${ }^{12}$ also obtained satisfactory results by applying adhesion lysis and debridement to treat intra-articulator adhesion.

\section{CONCLUSION}

The recent evolution of TMJ MRI allowed a higher quality visualization of intra articular structures, especially the articular disc, making it the exam of choice for the evaluation of disc displacement and morphological abnormalities. This modality of exam provides a precise visualization of the retrodiscal junction and essential information for therapeutical evaluation of the articular disc and its ligaments.

\section{Collaborators}

DP MELO and LSAF OLIVEIRA were responsible for drafting, reviewing and revising the manuscript. ACA CARVALHO and ACC OENNING were responsible for image acquisition, enforcement of the methodology and reviewing the manuscript. AKG was responsible for the enforcement of the methodology and drafting the manuscript. PSF CAMPOS was responsible for reviewing and revising the manuscript.

lock of the temporomandibular joint. J Oral Maxillofac Surg. 1997;55(8):797-802. doi: 10.1016/S0278-2391(97)90335-9.

7. Kaminishi RM, Davis CL. Temporomandibular joint arthroscopic observations of superior space adhesions. Oral Maxillofac Surg Clin North Am. 1989;1:103-9.

8. Sanromán JF. Closed lock (MRI fixed disk): a comparison of arthrocentesis and arthroscopy. Int J Oral Maxillofac Surg. 2004;33(4):344-8. doi: 10.1016/j.jjom.2003.10.005.

9. Nitzan DW. Friction and adhesive forces: possible underlying causes for temporomandibular joint internal derangement. Cells Tissues Organs. 2003;174(1-2):6-16. doi: 10.1159/000070570.

10. Rao VM, Liem MD, Farole A, Razek AAKA. Elusive stuck disk in the temporomandibular joint: Diagnosis with MR imaging. Radiology. 1993;189(3):823-7.

11. Zhang SY, Huang D, Llu XM, Yang C, Undt G, Haddad M, et al. Arthroscopic treatment for intra-articular adhesions of the temporomandibular joint. J Oral Maxillofac Surg. 2011;69(8):2120-7. doi: 10.1016/j.joms.2010.12.039.

12. Mosby EL. Efficacy of temporomandibular joint arthroscopy: a retrospective study. J Oral Maxillofac Surg. 1993;51(1):17-21.

Received on: 19/8/2013 Final version resubmitted on: 6/10/2013 Approved on: 29/10/2013 